\title{
Yellow foxtail [Setaria pumila (Poir.) Roem. \& Schult.] in crops of Cieszyńskie Foothills
}

\author{
Włośnica sina [Setaria pumila (Poir.) Roem. \& Schult.] \\ w uprawach rolniczych Pogórza Cieszyńskiego
}

Eugeniusz Chwastek ${ }^{1}$, Robert Idziak ${ }^{2 *}$, Hubert Waligóra ${ }^{2}$

Summary

In the mid-twentieth century in the Cieszyńskie Foothills Setaria pumila was recorded as a rare weed in potato crops, in the 1980 s - as a species of weed accompanying root crops, and less frequently, it could be found in ruderal areas. Currently, S. pumila occurs both in ruderal habitats, on the banks of waters, in the vicinity of expressways and, above all, in agricultural crops. Setaria pumila is present in almost all crops of the Cieszyńskie Foothills. In the vast majority of the indicated groups it appears very abundantly, often creating a form of facies. Together with Amaranthus retroflexus L., Avena fatua L. and Solanum nigrum L., it has become a serious problem in the Cieszyńskie Foothills. Most of the distinguished groups show disorders in the species composition, where the characteristic species of the group are often accompanied by species of other units (groups) or vice versa - calciphile species appear in acidophilic groups.

Key words: yellow foxtail, Cieszyńskie Foothills, agricultural crops

\section{Streszczenie}

W połowie XX wieku Setaria pumila na Pogórzu Cieszyńskim notowana była jako rzadki chwast w uprawach ziemniaka, w latach 80. ubiegłego wieku jako gatunek chwastu towarzyszący uprawom roślin okopowych, a także rzadziej na terenach ruderalnych. Obecnie S. pumila występuje zarówno na siedliskach ruderalnych, na brzegach wód, w sąsiedztwie dróg szybkiego ruchu oraz przede wszystkim w uprawach rolniczych. Swoją obecność S. pumila zaznacza prawie we wszystkich uprawach rolniczych Pogórza Cieszyńskiego. W zdecydowanej większości wskazanych zespołów pojawia się bardzo obficie, tworząc często postać facji. Wraz z Amaranthus retroflexus L., Avena fatua L. i Solanum nigrum L. zaczyna stanowić poważny problem w uprawach Pogórza Cieszyńskiego. Większość z wyróżnionych zespołów wykazuje zaburzenia w składzie gatunków, gdzie często gatunkom charakterystycznym zespołu towarzyszą gatunki innych jednostek (zespołów) lub odwrotnie - w zespołach acydofilnych pojawiają się gatunki kalcyfilne.

Słowa kluczowe: włośnica sina, Pogórze Cieszyńskie, uprawy rolnicze

\author{
${ }^{1}$ III Liceum Ogólnokształcące im. Stanisława Wyspiańskiego \\ Elfów 62, 43-100 Tychy \\ ${ }^{2}$ Uniwersytet Przyrodniczy w Poznaniu \\ Dojazd 11, 60-632 Poznań \\ *corresponding author: robert.idziak@up.poznan.pl \\ ORCID: 0000-0002-1621-9184
}




\section{Wstęp / Introduction}

Zachwaszczenie upraw jest jednym z głównych czynników wpływających na efektywność plonowania roślin. Według Latowskiego i Celki (2010) człowiek istotnie ingeruje w agrocenozy, a związane jest to z metodami uprawy, nawożeniem, aplikacją herbicydów oraz zmianami w strukturze zasiewów i płodozmianach. Ponadto skład zbiorowisk roślinności segetalnej w roślinach uprawnych warunkowany jest czynnikami środowiskowymi i klimatycznymi. Intensyfikacja działań rolnika powoduje znaczne zmiany w składzie zachwaszczenia upraw, co prowadzi do eliminacji niektórych gatunków chwastów, ale powoduje jednocześnie kompensację innych. Jednym z takich gatunków jest włośnica sina Setaria pumila (Poir.) Roem. \& Schult. Potrzeba analizy występowania tego chwastu w uprawach rolniczych Pogórza Cieszyńskiego wynikała z faktu, iż gatunek ten w połowie XX wieku był notowany sporadycznie w roślinach uprawnych (Pelc 1967; Zając 1989), głównie okopowych, a obecnie stwierdza się jego występowanie praktycznie we wszystkich uprawach tego regionu.

Problem S. pumila w uprawach rolniczych był obiektem badań zarówno instytutów naukowych (Bojarszczuk i wsp. 2017), jak i pracowników jednostek naukowych, m.in. Uniwersytetu Łódzkiego (Warcholińska 1992), Uniwersytetu Marii Curie-Skłodowskiej w Lublinie (Kapeluszny i Haliniarz 2010), Uniwersytetu Śląskiego w Katowicach (Węgrzynek 2006). Aktualnie archeofit ten uważany jest za gatunek inwazyjny (Tokarska-Guzik i wsp. 2012).

Celem badań była ocena występowania gatunku $S$. pumila na polach uprawnych Pogórza Cieszyńskiego.

\section{Materiały i metody / Materials and methods}

Badania składu botanicznego zbiorowisk roślinnych towarzyszących uprawie roślin rolniczych przeprowadzono w latach 2002-2006. Obserwacje prowadzono w uprawie takich gatunków, jak pszenica ozima i jara, jęczmień jary, kukurydza i ziemniak. Zdjęcia fitosocjologiczne w każdej roślinie uprawnej wykonywane były na powierzchni $100 \mathrm{~m}^{2}$, której wybór był losowy i niezależny od stopnia zachwaszczenia, sposobów uprawy, przedplonu i zabiegów agrotechnicznych. Zdjęcia fitosocjologiczne w uprawach zbóż wykonywano w czerwcu, a w kukurydzy i ziemniaku w lipcu-sierpniu. Badania przeprowadzono na terenie powiatu cieszyńskiego (gminy: Brenna, Cieszyn, Dębowiec, Hażlach, Skoczów, Ustroń) i bielskiego (gminy: Jasienica, Jaworze), w 40 miejscowościach. Przez 5 lat badań wykonano w sumie 680 zdjęć, z czego 61 wykorzystano w opracowaniu tabel fitosocjologicznych.

W badaniach nad występowaniem $S$. pumila w uprawach rolniczych Pogórza Cieszyńskiego oraz przy zestawieniach zdjęć w tabele zespołów, posłużono się metodą fitosocjologiczną Braun-Blanqueta, stosowaną w tego rodzaju badaniach, przyjmując następujące oznaczenia: 5 - liczba osobników dowolna, pokrycie powierzchni zdjęcia powyżej 75\%; 4 - liczba osobników dowolna, pokrycie 50-75\%; 3 - liczba osobników dowolna, pokrycie 25-50\%; 2 - liczba osobników duża, pokrycie 5-25\%; 1 - liczba osobników 5-50, pokrycie $>5 \%$; + liczba osobników niewielka (2 do 5), pokrycie $<5 \%$; r - liczba osobników bardzo mała - 1 okaz (Pawłowski 1972; Woźniak i Soroka 2015). Opracowanie zespołów oparto na przewodniku do oznaczania zbiorowisk roślinnych Polski (Matuszkiewicz 2008). Nomenklaturę gatunkową przyjęto za listą gatunków roślin (Mirek i wsp. 2002). Kategorie gleb i kompleksów glebowych sklasyfikowano na podstawie mapy glebowej opracowanej przez Instytut Uprawy Nawożenia i Gleboznawstwa w Puławach (IUNG 2006).

Setaria pumila jest gatunkiem z rodziny wiechlinowatych (Poaceae). W fitosocjologii uważana jest za gatunek charakterystyczny związku Panico-Setarion Siss. 1946. Związek ten dotyczy zbiorowisk chwastów w uprawach okopowych na uboższych i średnio żyznych piaskach gliniastych (Matuszkiewicz 2008). Setaria pumila jest trawą kępkową, jednoroczną, jarą. Pędy generatywne osiągają wysokość od 10 do $130 \mathrm{~cm}$. Jest gatunkiem ciepłolubnym (Zarzycki i wsp. 2002), okres kwitnienia przypada od lipca do października. Liczba wytwarzanych ziarniaków waha się od 150 do 200 sztuk, zachowujących zdolność kiełkowania w glebie do kilkunastu lat (Kozłowski 2012).

\section{Wyniki i dyskusja / Results and discussion}

Analiza wykonanych zdjęć fitosocjologicznych wykazała występowanie S. pumila w zespołach segetalnych, w prawie wszystkich uprawach rolniczych. Wyjątkiem był owies i rzepak ozimy, gdzie $S$. pumila pojawiała się sporadycznie. W uprawach objętych badaniami wykazano obecność sześciu zespołów (tab. 1, 2), których systematyka według Matuszkiewicza (2008) przedstawia się następująco:

Klasa (Cl.) Stellarietea mediae R. Tx. et Prsg. 1950

Rząd (O.) Centauretalia cyani R. Tx. 1950

Związek (All.): Aperion spicae-venti R.Tx. et J. Tx. 1960

Zespół (Ass.): Vicietum tetraspermae (Krusem et Vlieg.

1930) Kornaś 1950 (mieszanki zbóż jarych)

Związek (All.): Caucalidion lappulae R. Tx. 1950

Zespół (Ass.): Geranio-Silenetum gallicae Kornaś

(1950) 1968 (pszenica jara)

Zespół (Ass.): Kickxietum spuriae Krusem et Vlieg. 1939 (pszenica ozima)

Rząd (O.) Polygono-Chenopodietalia (R. Tx. et Lohm. 1950) 
Tabela 1. Liczba gatunków w zespołach segetalnych Pogórza Cieszyńskiego Table 1. Number of species in plant association of Cieszyńskie Foothills

\begin{tabular}{|c|c|c|c|c|c|}
\hline $\begin{array}{c}\text { Zespół } \\
\text { Association }\end{array}$ & $\begin{array}{l}\text { Uprawa } \\
\text { Crop }\end{array}$ & $\begin{array}{l}\text { Ogólna liczba } \\
\text { gatunków } \\
\text { Total numer } \\
\text { of species }\end{array}$ & $\begin{array}{c}\text { Liczba gatunków } \\
\text { z Cl. Stellarietea } \\
\text { mediae } \\
\text { Number of species } \\
\text { in Cl. Stellarietea } \\
\text { mediae }\end{array}$ & $\begin{array}{c}\text { Liczba } \\
\text { pozostałych } \\
\text { gatunków } \\
\text { Number } \\
\text { of other species }\end{array}$ & $\begin{array}{c}\text { Średnia liczba } \\
\text { gatunków } \\
\text { w zdjęciu } \\
\text { Average number } \\
\text { of species } \\
\text { in the releves }\end{array}$ \\
\hline Vicietum tetraspermae & $\begin{array}{l}\text { ziemniak } \\
\text { potato }\end{array}$ & 79 & 39 & 40 & 25 \\
\hline Geranio-Silenetum gallicae & $\begin{array}{l}\text { pszenica jara } \\
\text { spring wheat }\end{array}$ & 71 & 37 & 34 & 25 \\
\hline Kickxietum spuriae & $\begin{array}{l}\text { pszenica ozima } \\
\text { winter wheat }\end{array}$ & 59 & 27 & 32 & 22 \\
\hline Echinochloo-Setarietum & $\begin{array}{l}\text { ziemniak } \\
\text { potato }\end{array}$ & 65 & 34 & 31 & 25 \\
\hline Galinsogo-Setarietum & $\begin{array}{l}\text { pszenica jara } \\
\text { spring wheat }\end{array}$ & 60 & 28 & 32 & 25 \\
\hline Galinsogo-Setarietum & $\begin{array}{c}\text { pszenica ozima } \\
\text { winter wheat }\end{array}$ & 60 & 33 & 27 & 27 \\
\hline Oxalido-Chenopodietum polyspermi & $\begin{array}{c}\text { pszenica ozima } \\
\text { winter wheat }\end{array}$ & 61 & 29 & 32 & 25 \\
\hline Oxalido-Chenopodietum polyspermi & $\begin{array}{l}\text { kukurydza } \\
\text { maize }\end{array}$ & 54 & 27 & 27 & 23 \\
\hline Oxalido-Chenopodietum polyspermi & $\begin{array}{l}\text { jęczmień jary } \\
\text { spring barley }\end{array}$ & 51 & 20 & 31 & 26 \\
\hline
\end{tabular}

Tabela 2. Występowanie Setaria pumila w zespołach segetalnych Pogórza Cieszyńskiego Table 2. Occurrence of Setaria pumila in plant association of Cieszyńskie Foothills

\begin{tabular}{|c|c|c|c|c|c|c|c|c|c|c|}
\hline \multirow{3}{*}{$\begin{array}{c}\text { Zespół } \\
\text { Association }\end{array}$} & \multicolumn{10}{|c|}{$\begin{array}{l}\text { Wartość wskaźnika w skali Braun-Blanqueta } \\
\text { Value of Braun-Blanquet indicator }\end{array}$} \\
\hline & \multicolumn{2}{|c|}{$\begin{array}{l}\text { ziemniak } \\
\text { potato }\end{array}$} & \multicolumn{2}{|c|}{$\begin{array}{l}\text { pszenica jara } \\
\text { spring wheat }\end{array}$} & \multicolumn{2}{|c|}{$\begin{array}{l}\text { pszenica ozima } \\
\text { winter wheat }\end{array}$} & \multicolumn{2}{|c|}{$\begin{array}{l}\text { kukurydza } \\
\text { maize }\end{array}$} & \multicolumn{2}{|c|}{$\begin{array}{l}\text { jęczmień jary } \\
\text { spring barley }\end{array}$} \\
\hline & $\min$ & $\max$ & $\min$ & $\max$ & $\min$ & $\max$ & $\min$ & $\max$ & $\min$ & $\max$ \\
\hline Vicietum tetraspermae & $\mathrm{r}$ & $+0,2$ & - & - & - & - & - & - & - & - \\
\hline Geranio-Silenetum gallicae & - & - & + & 2,3 & - & - & - & - & - & - \\
\hline Kickxietum spuriae & - & - & - & - & $+0,2$ & 3,4 & - & - & - & - \\
\hline Echinochloo-Setarietum & $\mathrm{r}$ & 1,2 & - & - & - & - & - & - & - & - \\
\hline Galinsogo-Setarietum & - & - & + & 4,4 & $+0,3$ & 3,4 & - & - & - & - \\
\hline Oxalido-Chenopodietum polyspermi & - & - & - & - & $\mathrm{r}$ & 1,2 & $\mathrm{r}$ & 1,2 & $\mathrm{r}$ & 3,4 \\
\hline
\end{tabular}

$\mathrm{r}$ - liczba osobników bardzo mała - 1 okaz - number of individuals very low - 1 sample

Związek (All.): Panico-Setarion Siss. 1946

Zespół (Ass.): Echinochloo-Setarietum (Krusem et Vlieg. 1939) 1940 (ziemniak)

Związek (All.): Polygono-Chenopodion Siss. 1946

Zespół (Ass.): Galinsogo-Setarietum Siss. 1946 (pszenica jara, pszenica ozima)

Zespół (Ass.): Oxalido-Chenopodietum polyspermii Siss. 1950 (pszenica ozima, jęczmień jary, kukurydza).

Wyróżnione zespoły cechuje zubożenie w gatunki charakterystyczne. $\mathrm{W}$ ich składzie istotnym elementem są ga- tunki archeofitów. Charakterystykę wyróżnionych zespołów segetalnych $\mathrm{z}$ udziałem $\mathrm{w}$ uprawach włośnicy sinej - S. pumila podano poniżej.

Vicietum tetraspermae (Kruseman i Vlieger 1939; Kornaś 1950; Wójcik 1977) jest najbardziej rozpowszechnionym zespołem (związku Aperion spicae-venti) w Polsce. Analizowane płaty odnotowano w uprawach mieszanek zbóż jarych. Jest najbogatszym w gatunki zespołem wykazanym w analizie (79 gatunków). Średnia liczba gatunków chwastów wynosiła 25. Liczba chwastów klasy Stellarie- 
tea mediae była równoważna pozostałym gatunkom. Powierzchnia pól wynosiła od 0,4 do 3,8 ha. W obrębie zespołu wyróżniono wariant ze szczawikiem zajęczym (Oxalis fontana L.) - charakterystycznym dla Oxalido-Chenopodietum polyspermi Siss. 1950, często występującym w obrębie dolin rzecznych i pogórzy (Roo-Zielińska i Solon 2001; Wójcik 2001). Zespół ten reprezentowany jest przez zubożałą postać, z nielicznymi gatunkami rzędu i związku. Setaria pumila występuje $\mathrm{w}$ wartościach od + do 2,2 . Istotnym jest pojawienie się postaci facji (w pojedynczych płatach) z obecnością babki lancetowatej (Plantago lanceolata L.) i rolnicy pospolitej (Sherardia arvensis L.), gatunku występującego powszechnie w uprawach Pogórza Cieszyńskiego i Gór Stołowych (Świerkosz i Wójcik 2018). Dość często w płatach pojawiają się gatunki kalcyfilne, np. owies głuchy i rolnica pospolita.

Geranio-Silenetum gallicae Kornaś (1950) 1968 to kalcyfilny zespół wikaryzujący z poprzednim, na siedliskach podobnych w obrębie pogórza fliszowego. Również bogaty w gatunki chwastów (71 gatunków), z przewagą gatunków klasy Stellarietea mediae, odnotowany został w uprawach pszenicy jarej. Powierzchnia pól nie przekraczała 1 ha. Średnia liczba gatunków w zdjęciu oscylowała $\mathrm{w}$ wartościach jak w poprzednim zespole. Jest to uboga postać zespołu, budowana głównie przez bodziszek porozcinany (Geranium dissectum L.), z pojedynczymi wystąpieniami wyki siewnej (Vicia sativa L.) i lepnicy francuskiej (Silene gallica L.) zagrożonej wyginięciem (CDPGŚ 2012).

Setaria pumila swoją obecność zaznacza słabo (pojedynczo osiąga wartość 2,2) w zespole Kickxietum spuriae Kruseman i Vlieger 1939, zespole kalcyfilnym, z rzadkimi gatunkami charakterystycznymi, takimi jak kiksja oszczepowata (Kickxia elatine L.) Dumort. i kiksja zgiętoostrogowa (Kickxia spuria L.) Dumort. - zagrożonymi wymarciem. Zespół ten, notowany na terenach Dolnego Śląska (Kącki i wsp. 1999), w obrębie Pogórza Cieszyńskiego występuje stosunkowo często. Analizowane uprawy o powierzchni od 1,0 do 3,0 ha, dotyczyły pszenicy ozimej. W stosunku do poprzednich zespołów mało liczny w gatunki chwastów (59), a gatunki klasy Stellarietea mediae ustępują pozostałym. W składzie gatunkowym zwraca uwagę obecność (facja) kalcyfilnego gatunku, jakim jest wilczomlecz drobny (Euphorbia exigua L.).

W przeważającej większości zdjęć S. pumila tworzy postać facji. Zespół Echinochloo-Setarietum (Kruseman i Vlieger 1939) 1940 jest najbardziej rozpowszechnionym zespołem wielkopowierzchniowych upraw w środkowej i południowej Polsce. Wyodrębniono go w ziemniaku, którego powierzchnia była niewielka, gdyż na Pogórzu Cieszyńskim jest on uprawiany sporadycznie. Zespół jest dość liczny w gatunki chwastów (66 gatunków, średnia liczba w płatach wynosiła 25), liczba gatunków reprezentujących klasę Stellarietea media równoważy się z pozo- stałymi. Wyodrębniono wariant $\mathrm{z}$ gatunkami charakterystycznymi dla zespołu Galinsogo-Setarietum z żółtlicą owłosioną [Galinsoga ciliata (Raf.) S.F. Blake] i żółtlicą drobnokwiatową (Galinsoga parviflora Cav.). Natomiast $S$. pumila występowaniem swym nawiązuje do obserwowanych na Śląsku Opolskim upraw ziemniaka (Szotkowski 1973).

Zespół Galinsogo-Setarietum Siss. 1946 jest zespołem małopowierzchniowych upraw i ogródków przydomowych. Na Pogórzu Cieszyńskim odnotowany został w uprawach pszenicy jarej (dość liczny w gatunki chwastów - 60, przy średniej liczbie w płatach wynoszącej $25-27$, z przewagą gatunków z klasy Stellarietea mediae). We wszystkich analizowanych płatach odnotowano obecność szczawika żółtego (Oxalis fontana Bunge), gatunku charakterystycznego dla Oxalido-Chenopodietum polyspermi. Setaria pumila znacząco zaznaczyła swą obecność przyjmując wartości od + do 4,4 (postać facji częściej była obserwowana w pszenicy jarej).

Oxalido-Chenopodietum polyspermii Siss. 1950 jest zespołem o charakterze azonalnym, związanym swoim występowaniem $\mathrm{z}$ dolinami rzecznymi oraz $\mathrm{w}$ obrębie pogórzy. Jest on typowym zespołem upraw okopowych, na glebach o odczynie obojętnym do zasadowego. Jest najczęściej notowanym zespołem z udziałem $S$. pumila. Płaty tego zespołu wyodrębniono w uprawach jęczmienia jarego, pszenicy ozimej i kukurydzy. W wymienionych uprawach stwierdzono brak komosy wielonasiennej (Chenopodium polyspermum L.), jednego $\mathrm{z}$ gatunków charakterystycznych dla tego zespołu.

Analizowane płaty $\mathrm{w}$ uprawach jęczmienia jarego cechowała dość duża liczba gatunków (60), przy średniej liczbie na powierzchniach badanych - 26 gatunków. Powierzchnia upraw nie przekraczała 2 ha. Gatunki z klasy Stellarietea mediae stanowiły połowę ogólnej liczby. W składzie gatunkowym zwraca uwagę obecność owsa głuchego (Avena fatua L.) (postać facji), gatunku charakterystycznego dla Centauretalia cyani. Setaria pumila występowała $\mathrm{w}$ wartościach od $\mathrm{r}$ do 3,4 .

W uprawie pszenicy ozimej ogólna liczba gatunków w przebadanych płatach wynosiła 60 , z nieznaczną przewagą reprezentujących klasę Stellarietea mediae. Średnia liczba gatunków badanych powierzchni wynosiła 25 . We wszystkich badanych płatach stwierdzono obecność wyki czteronasiennej [Vicia tetrasperma (L.) Schreb.], gatunku charakterystycznego dla Vicietum tetraspermae. Setaria pumila w uprawach pszenicy ozimej zaznaczyła zdecydowanie silniej swą obecność, w połowie zdjęć osiągając wartości 2,2, a w jednym płacie postać facji.

Uprawa kukurydzy na ziarno na Pogórzu Cieszyńskim stanowi, po mieszankach zbóż jarych i pszenicy ozimej, znaczną część powierzchni uprawnej (Chwastek 2008; GUS 2018). Skład gatunkowy chwastów w kukurydzy jest najuboższy - 54 gatunki, liczba gatunków z klasy Stellarietea 
mediae jest równa pozostałym gatunkom i wynosi 27 . Kukurydzy towarzyszą dość licznie gatunki charakterystyczne dla rzędu Polygono-Chenopodietalia i Polygono-Chenopodion. Na tych plantacjach $S$. pumila osiągała wartości od r do 1,2. Istotnym dla kukurydzy jest również częste i masowe występowanie inwazyjnego i już na stałe zadomowionego chwastu, jakim jest Amaranthus retroflexus L.

\section{Wnioski / Conclusions}

1. Występowanie S. pumila związane jest z jego biologią, w tym przede wszystkim późnym kiełkowaniem i wschodami.
2. Problemy z występowaniem $S$. pumila w różnych uprawach rolniczych wynikają ze zmiany struktury zasiewów, zwłaszcza rezygnacji z roślin okopowych. W takiej sytuacji S. pumila zmuszona jest niejako do „szukania” innych, zastępczych siedlisk.

3. Wyodrębnione zespoły wykazują zaburzenia składu gatunkowego typowego dla badanych upraw rolniczych, czego skutkiem jest pojawianie się w zespołach gatunków $\mathrm{z}$ innych klas, tj. Molinio-Arrhenatheretea, Artemisietea vulgaris.

4. Dla określenia stopnia zagrożenia ekspansją S. pumila niezbędny jest dalszy monitoring zmian w składzie zbiorowisk chwastów w obrębie pól uprawnych.

\section{Literatura / References}

Bojarszczuk J., Księżak J., Staniak M., Czopek K. 2017. Zachwaszczenie kukurydzy uprawianej współrzędnie z wybranymi gatunkami roślin. [Evaluation of weed infestation of maize cultivated in mixed sowing with selected plant species]. Journal of Research and Applications in Agricultural Engineering 62 (3): 49-53.

CDPGS 2012. Czerwone listy wybranych grup grzybów i roślin województwa Śląskiego. Raporty Opinie 6. Strategia ochrony przyrody województwa śląskiego do roku 2030. Raport o stanie przyrody województwa śląskiego. Centrum Dziedzictwa Przyrody Górnego Śląska, Katowice, 177 ss.

Chwastek E. 2008. Zbiorowiska segetalne Pogórza Cieszyńskiego. Praca doktorska. Uniwersytet Śląski w Katowicach, 149 ss.

GUS 2018. Rocznik Statystyczny Rolnictwa. Główny Urząd Statystyczny, Warszawa, 453 ss.

IUNG Puławy 2006. Pogórze Śląskie. Mapa glebowo rolnicza. Mapa numeryczna w skali $1: 75000$.

Kapeluszny J., Haliniarz M. 2010. Ekspansywne i zagrożone gatunki flory segetalnej w środkowo-wschodniej Polsce. Annales Universitatis Mariae Curie-Skłodowska Lublin, Sectio E, Agricultura 65 (1): 26-33.

Kącki Z., Anioł-Kwiatkowska J., Dajdok Z. 1999. Kickxietum spuriae - nowy dla Polski zespół chwastów segetalnych. [Kickxietum spuriae - an association of segetal weeds new to Poland]. Fragmenta Floristica et Geobotanica - Series Polonica 6: 119-125.

Kornaś J. 1950. Les associations végétales du Jura Cracovien. I-ére partie: Les associations des champs cultivés. Acta Societatis Botanicorum Poloniae 20 (2): 361-438.

Kozłowski S. 2012. Trawy. Państwowe Wydawnictwo Rolnicze i Leśne, Poznań, 274 ss.

Kruseman G., Vlieger J. 1939. Akkerassociaties in Nederland. Nederlandsch Kruidkundig Archief 49: 327-398.

Latowski K., Celka Z. 2010. IX Międzynarodowa Konferencja „Synantropizacja środowiska i terenów osiedli wiejskich. Flora i roślinność" (Kamieniec Podolski, Ukraina, 29 czerwca - 1 lipca 2010). [Ninth International Conference 'Anthropization and environment of rural settlements. Flora and vegetation' (Kamyanets-Podilsky, Ukraine, 29 June - 1 July 2010)]. Wiadomości Botaniczne 54 (1/2): 61-64.

Matuszkiewicz W. 2008. Przewodnik do oznaczania zbiorowisk roślinnych Polski. Państwowe Wydawnictwo Naukowe, Warszawa, 181 ss.

Mirek Z., Piękoś-Mirkowa H., Zając A., Zając M., Bernacki L., Cieślak E., Głowacki Z., Leda M., Mitka J., Paśnik A., Paul W., Ronikier M., Rostański K., Szeląg Z., Wójcicki J.J., Zalewska-Gałosz J., Zieliński J., Żukowski W. 2002. Flowering plants and pteridophytes of Poland. A checklist. Series: Biodiversity of Poland, Vol. 1. Instytut Botaniki im. W. Szafera, Polska Akademia Nauk, Kraków, 442 ss. ISBN 83-85444-83-1.

Pawłowski B. 1972. Skład i budowa zbiorowisk roślinnych oraz metody ich badania. s. 237-268. W: Szata roślinna Polski, T. I (W. Szafer, K. Zarzycki, red.). Państwowe Wydawnictwo Naukowe, Warszawa.

Pelc S. 1967. Rośliny naczyniowe Pogórza Cieszyńskiego. Rocznik Naukowo-Dydaktyczny. WSP w Krakowie 28: 109-208.

Roo-Zielińska E., Solon J. 2001. Typologia zbiorowisk i kartografia roślinności w Polsce: rozważania nad stanem współczesnym. Instytut Geografii i Przestrzennego Zagospodarowania Polskiej Akademii Nauk, Warszawa, 273 ss.

Szotkowski P. 1973. Chwasty zbóż ozimych i upraw okopowych na Śląsku Opolskim. Prace Opolskiego Towarzystwa Przyjaciół Nauk, Wydział III: Nauk Przyrodniczych. Państwowe Wydawnictwo Naukowe, Warszawa-Wrocław, 33 ss.

Świerkosz K., Wójcik G. 2018. Flora Gór Stołowych. s. 329-350. W: Góry Stołowe - przyroda i ludzie. Park Narodowy Gór Stołowych, Kudowa Zdrój, 456 ss. ISBN 978-83-938085-7-1.

Tokarska-Guzik B., Dajdok Z., Zając A., Zając M., Urbisz A., Danielewicz W., Hołdyński C. 2012. Rośliny obcego pochodzenia w Polsce ze szczególnym uwzględnieniem gatunków inwazyjnych. Generalna Dyrekcja Ochrony Środowiska, Warszawa, 197 ss.

Warcholińska A.U. 1992. Występowanie niektórych gatunków chwastów na glebach różnych kompleksów województwa skierniewickiego. [Occurence of certain weed species on the various soil com plexes of the skierniewice voivodship]. Acta Universitatis Lodziensis, Folia Botanica 9: 23-39.

Węgrzynek B. 2006. Roślinność segetalna Wyżyny Śląskiej. Cz. V. Zbiorowiska chwastów upraw okopowych ze związku Eu-PolygonoChenopodiom polyspermi (Koch 1926) Siss. 1946. / Segetal vegetation of the Silesian Upland. Part V. Root crop weed communities of the Eu-Polygono-Chenopodion polyspermi (Koch 1946) Siss. 1946 Alliance. Weed communities of maize crop. Natura Silesiae Superioris, Centrum Dziedzictwa Przyrody Górnego Śląska 9 (2005): 63-83. 
Woźniak A., Soroka M. 2015. Syntaksonomiczna ocena zbiorowisk chwastów w zasiewach żyta (Secale cereale L.) na polach ukraińskiego Roztocza. [Syntaxonomic evaluation of weed communities in rye in the Ukrainian Roztocze]. Fragmenta Agronomica 32 (2): 97-110.

Wójcik Z. 1977. Charakterystyka siedlisk polnych na Pogórzu Beskidu Niskiego metodami biologicznymi. Prace Geograficzne 121, Instytut Geografii i Przestrzennego Zagospodarowania Polskiej Akademii Nauk, 106 ss.

Wójcik Z. 2001. Oxalido-Chenopodietum polyspermi Sissingh 1942 - zespół upraw okopowych dolin rzecznych i pogórzy w Polsce. Typologia i kartografia roślinności w Polsce. Prace Geograficzne, Instytut Geografii i Przestrzennego Zagospodarowania Polskiej Akademii Nauk, 178 ss.

Zając M. 1989. Flora południowej części Kotliny Oświęcimskiej i Pogórza Śląskiego. [Flora of the southern part of the Oświęcim Basin and Silesian Foothills]. Zeszyty Naukowe Uniwersytetu Jagielońskiego, Prace Botaniczne 19, 199 ss.

Zarzycki K., Trzcińska-Tacik H., Różański W., Szeląg Z., Wołek J., Korzeniak U. 2002. Ecological indicator values of vascular plants of Poland. [Ekologiczne liczby wskaźnikowe roślin naczyniowych Polski]. Instytut Botaniki im. W. Szafera, Polska Akademia Nauk, Kraków, 183 ss. 